\title{
Multi-modal approach to treatment in advanced adrenocortical carcinoma
}

\author{
L Hall1, C Perry', N Reed ${ }^{2}$, E Leen ${ }^{3}$, H Wasan ${ }^{4}$, M Freel1
}

1 Endocrine Unit, Western Infirmary, Glasgow 2 Beatson West of Scotland Cancer Centre, Glasgow 3 Dept. of Radiology, Imperial College London

4 Dept. of Medical Oncology, Hammersmith Hos 2

Introduction

A 38 year old HR manager presented in 2008,9 months post partum with acne, facial hirsutism and upper abdominal discomfort. On examination she was normotensive, virilised and with an easily palpable mass arising from the right upper quadrant.

\section{Biochemistry}

Androstenedione $93.9 \mathrm{nmol} / \mathrm{l}$

DHAS $37.7 \mathrm{umol} / \mathrm{I}$

17 OHP $13 \mathrm{nmol} / \mathrm{l}$

Testosterone $13.7 \mathrm{nmol} / \mathrm{l}$

Oestradiol $157 \mathrm{pmol} / \mathrm{I}$

LH, FSH undetectable

SHBG $53 \mathrm{nmol} / \mathrm{l}$

ODST cortisol $<25 \mathrm{nmol} / \mathrm{I}$

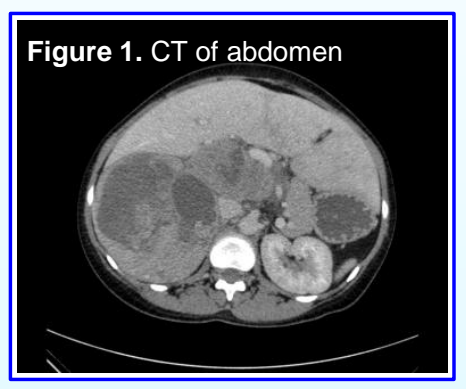

U\&Es normal (K $3.3 \mathrm{mmol} / \mathrm{l})$

Alk phos $174 \mathrm{mU} / \mathrm{l}$, alb $26 \mathrm{~g} / \mathrm{l}$

TSH $2.5 \mathrm{mU} / \mathrm{l}, \mathrm{fT} 413 \mathrm{pmol} / \mathrm{l}$

Glu $6.7 \mathrm{mmol} / \mathrm{l}$

CRP $100 \mathrm{mg} / \mathrm{l}$

$\mathrm{Ca}^{2+}(\mathrm{adj}) 2.49 \mathrm{mmol} / \mathrm{l}$

AFP $7 \mathrm{KU} / \mathrm{I}$

24 hour urine cats/mets normal Imaging

- Large heterogeneous right adrenal tumour $(18 \times 12 \times 10 \mathrm{~cm})$

- Similar mass right lobe of liver

- Compression of IVC with extensive IVC + femoral vein thrombus

Immediate management

- IVC filter

- Mitotane chemotherapy (+hydrocortisone)

Surgical mananagement

- Right adrenalectomy with extended right hepatectomy

- Common bile duct excision

Portal vein reconstruction + IVC excision/ replacement allogenic iliac vein graft

Pathology revealed adrenocortical carcinoma

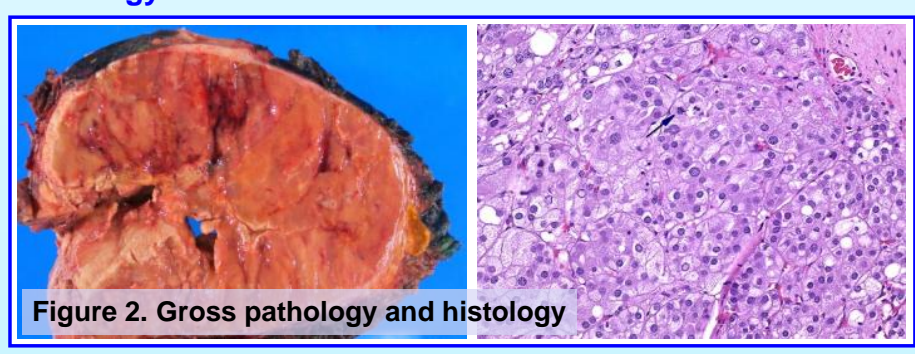

Further mananagement

- 1st cycle chemotherapy with doxorubicin, cisplatin + etoposide in addition to mitotane October 2008

- chemo $\mathbf{R}$ adrenalectomy

- Extended R hepatectomy

- Common bile duct excision

- Portal vein reconstruction + IVC excision/ replacement, allogenic iliac vein graft

\section{Progress}

- Difficulty achieving therapeutic serum levels of mitotane because of toxicity

- Recurrence in May 2010 with 2 hepatic metastases

- Surgical exploration revealed multiple hepatic metastases, so further resection not attempted

- Tumour sample sent to Portsmouth hospital for in vitro culture, but no growth occurred

- Radiofrequency ablation (RFA) to liver metastases in June 2010

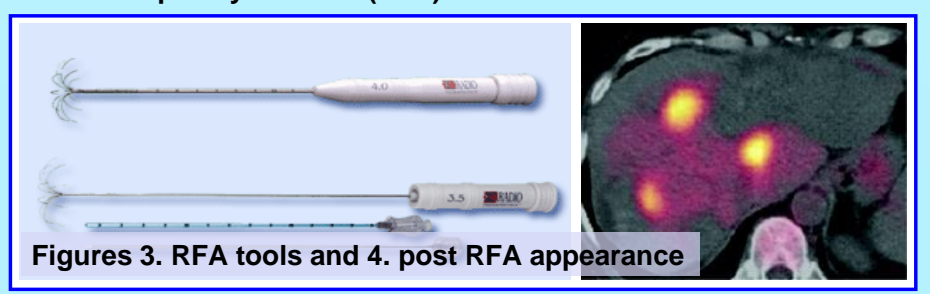

Further disease progression on mitotane with lung and new hepatic metastases

- Biopsy for chemo-sensitivity testing suggestive of resistance to doxorubicin and cisplatin and sensitivity to irinotecan

- Further RFA to hepatic and lung metastases in Feb 2011

- Further disease progression in Aug 2011 despite completion of an additional course of chemotherapy

- Sunitinib started, mitotane stopped Sep 11

- Tumour stimulation with Irreversible Electroporation (IRE) - $50 \%$ reduction in hepatic blood flow seen on ultrasound

- Feb 2012 - no disease progression

- May 2012 - improvement/ partial response to treatment. Possibility of selective resistance in part of the liver

- Oct 2012 - nanoknife ablation of non-responsive hepatic metastases and sunitinib dose increased. Imaging shows stable disease
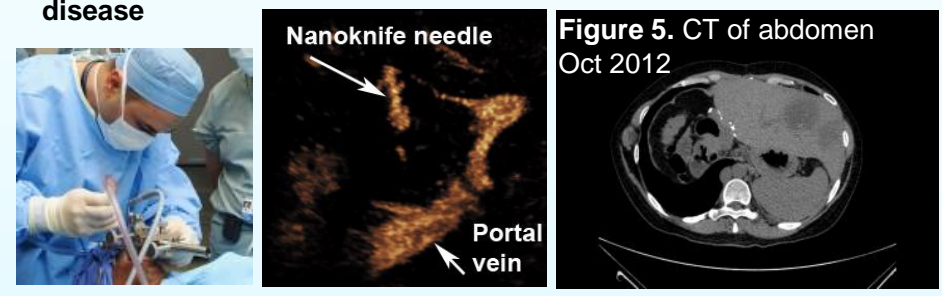

- Jan 2013 - Patient remains well although is cortisol deficient even after stopping mitotane. Androgens are suppressed (testosterone $<0.5 \mathrm{nmol} / \mathrm{l}$, a'dione $4.7 \mathrm{nmol} / \mathrm{l}$, DHAS $2.9 \mathrm{umol} / \mathrm{l}$ ).

\section{Discussion}

Adrenocortical carcinoma (ACC) is a rare aggressive tumour with a median five year survival of $10-25 \%$ when it presents with advanced stage disease ${ }^{1}$, and in most cases metastatic disease is fatal within 1 year, although there are a small number of case reports of long-term responses to chemotherapy $+/-$ mitotane ${ }^{2,3}$.

Surgical resection, when possible, is the mainstay of treatment and a 2007 European retrospective analysis supported the use of adjuvant mitotane ${ }^{4}$, which is now frequently used. Adjuvant radiotherapy is not thought to be beneficial, although there is a lack of RCT evidence investigating its efficacy in patients with resected ACC.

It is not known whether cytotoxic chemotherapy alone or in combination with mitotane is more effective than mitotane alone. There are also little published data on RFA in metastatic ACC, but 2 small studies (both $n=8$ ) have demonstrated safety and short-term efficacy in terms of tumour shrinkage ${ }^{5}$, and median survival of 1.9 years post RFA 6 respectively.

Pre-clinical studies exploring the use of the multi-targeted receptor tyrosine kinase inhibitor sunitinib in ACC are promising ${ }^{7}$ although the few published cases and a small clinical trial of use of sunitinib in metastatic ACC report variable outcomes ${ }^{8,9}$.

This is a highly unusual case of prolonged survival in aggressive ACC with the use of multiple therapeutic modalities, many of which have a paucity of clinical evidence.

\section{References}

1. Luton JP et al: Clinical features of adrenocortical carcinoma, prognostic factors, and the effect of mitotane therapy. N.Engl.J Med. 322, 1195-1201 (1990) 2. De Leon DD et al: Long-term (15 years) outcome in an infant with metastatic adrenocortical carcinoma. J Clin.Endocrinol.Metab. 87, 4452-4456 (2002) 3. Sperone P et al: Longterm disease free survival in a patient with metastatic adreno-cortical carcinoma after complete pathological response to chemotherapy plus mitotane. J Endocrinol.Invest. 29, 560-562 (2006) 4. Terzolo M et al: Adjuvant mitotane treatment for adrenocortical carcinoma. N.Engl.J Med. 356, 2372-2380 (2007) 5. Wood BJ et al: Radiofrequency ablation of adrenal tumors and adrenocortical carcinoma metastases. Cancer. 97, 554-560 (2003) 6. Ripley RT et al: Liver resection and ablation for metastatic adrenocortical carcinoma. Ann.Surg.Oncol. 18, 1972-1979 (2011) 7. Kroiss M et al: Sunitinib Inhibits Cell Proliferation and Alters Steroidogenesis by Down-Regulation of HSD3B2 in Adrenocortical Carcinoma Cells. Front Endocrinol. 2, 27 (2011) 8. Kroiss M et al: Sunitinib in refractory adrenocortical carcinoma: a phase II, single-arm, open-label trial. J Clin.Endocrinol.Metab. 9.3495-3503 (2012) 9. Lee JO et al: Metastatic adrenocortical carcinoma treated with sunitinib:a case report. Jpn.J Clin. Oncol. 39, 183-185 (2009)

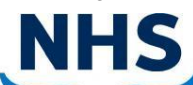

Greater Glasgow and Clyde 